\title{
OPEN Rhizosphere enzyme activities and microorganisms drive the transformation of organic and inorganic carbon in saline-alkali soil region
}

\author{
Yunke Qu ${ }^{1,2}$, Jie Tang ${ }^{2}$, Ben Liu², Hang Lyu², Yucong Duan², Yao Yang ${ }^{2}$, Sining Wang² \& \\ Zhaoyang $\mathrm{Li}^{2 \bowtie}$
}

Western Jilin Province is one of the world's three major saline-alkali land distribution areas, and is also an important area of global climate change and carbon cycle research. Rhizosphere soil microorganisms and enzymes are the most active components in soil, which are closely related to soil carbon cycle and can reflect soil organic carbon (SOC) dynamics sensitively. Soil inorganic carbon (SIC) is the main existing form of soil carbon pool in arid saline-alkali land, and its quantity distribution affects the pattern of soil carbon accumulation and storage. Previous studies mostly focus on SOC, and pay little attention to SIC. Illumina Miseq high-throughput sequencing technology was used to reveal the changes of community structure in three maize fields (M1, M2 and M3) and three rice fields (R1, R2 and R3), which were affected by different levels of salinization during soil development. It is a new research topic of soil carbon cycle in saline-alkali soil region to investigate the effects of soil microorganisms and soil enzymes on the transformation of SOC and SIC in the rhizosphere. The results showed that the root-soil-microorganism interaction was changed by saline-alkali stress. The activities of catalase, invertase, amylase and 6 -glucosidase decreased with increasing salinity. At the phylum level, most bacterial abundance decreases with increasing salinity. However, the relative abundance of Proteobacteria and Firmicutes in maize field and Firmicutes, Proteobacteria and Nitrospirae in rice field increased sharply under saline-alkali stress. The results of redundancy analysis showed that the differences of rhizosphere soil between the three maize and three rice fields were mainly affected by ESP, pH and soil salt content. In saline-alkali soil region, b-glucosidase activity and amylase were significantly positively correlated with $\mathrm{SOC}$ content in maize fields, while catalase and b-glucosidase were significantly positively correlated with SOC content in rice fields. Actinobacteria, Bacteroidetes and Verrucomicrobia had significant positive effects on SOC content of maize and rice fields. Proteobacteria, Gemmatimonadetes and Nitrospirae were positively correlated with SIC content. These enzymes and microorganisms are beneficial to soil carbon sequestration in salinealkali soils.

Soil carbon pool is the largest carbon pool in terrestrial ecosystems. Its dynamic change and driving mechanism are the focus and hotspot of terrestrial ecosystem carbon cycle and global change research, and also one of the core issues of global change research programs such as the Global Carbon Project (GCP) and World Climate Research Program (WCRP) ${ }^{1}$. Soil carbon pool mainly includes soil organic carbon (SOC) pool and inorganic carbon (SIC) pool. SOC plays a dominant role in soil carbon pool in humid areas, while SIC is the main form of carbon in arid and semi-arid areas with annual rainfall less than $400 \mathrm{~mm}^{2,3}$. It is estimated that the global SOC pool is as high as $1.4-1.5 \times 10^{18} \mathrm{~g} \mathrm{C}$, which is about 2.4 times of the total terrestrial biological carbon and 3 times of the total atmospheric carbon ${ }^{4}$. A change of $0.1 \%$ in soil carbon pool will increase atmospheric $\mathrm{CO}_{2}$ concentration by $1 \mathrm{mg} \mathrm{m}^{-3}$ and have a profound impact on global climate change.

${ }^{1}$ Key Lab of Groundwater Resources and Environment, Ministry of Education, Jilin University, Changchun 130012, China. ${ }^{2}$ College of New Energy and Environment, Jilin University, Changchun 130012, China. ${ }^{\boxplus}$ email: zhaoyang@ jlu.edu.cn 
Soil enzymes are ubiquitous in soil and can be considered as one of the most active components in soil, which can promote the mineralization and decomposition of SOM and release inorganic nutrients ${ }^{5-7}$. Soil $\mathrm{pH}$ directly affects the speed at which soil enzymes participate in biochemical reactions, and when $\mathrm{pH}$ exceeds its optimum range, enzyme activity will be inhibited ${ }^{8}$. Studies have shown that oxidase activity is more affected by soil $\mathrm{pH}^{9}$. Zhang et al. ${ }^{10}$ found that soil enzyme activity was also affected by saline-alkali stress, and soil salt content (SSC) in salinized soil was significantly negatively correlated with enzyme activities such as hydrooxidase and invertase. The relationship between soil $\mathrm{pH}$ and enzyme activity also has a controlling effect on SOC ${ }^{11}$. From a global perspective, Sinsabaugh et al. ${ }^{12}$. concluded that hydrolase activity was more related to SOC. This finding suggests that hydrolases may be more important for the decomposition of SOC, with implications for nutrients and carbon cycling. Marx et al. ${ }^{13}$ studied the distribution of hydrolases related to soil nutrients and found that the enzyme activity related to carbon cycling was the highest in coarse sand. The study on the activity changes of various enzymes is of great significance for revealing the process of SOM transformation.

Soil microorganism plays a key role in regulating matter circulation of ecosystem and is an important index to measure soil properties and functions ${ }^{14}$. The exchange of matter and energy between soil, rhizosphere micr oorganisms, and plants forms a close and special relationship, which makes the abundance and species of rhizosphere microorganisms differ to some extent from those of non-rhizosphere soils ${ }^{15}$. Soil physico-chemical properties, nutrient cycling and microbial activity are affected by the type of soil tillage ${ }^{16}$. The changes of soil temperature, moisture and carbon input will also have a great effect on soil microbial activity, which in turn will affect the nutrient availability due to the turnover of $\mathrm{SOM}^{17}$. Lenton et al. ${ }^{18}$ showed that the increase of temperature led to the change of microbial community structure, which accelerated the decomposition rate of SOC and released the carbon stored in the soil into the atmosphere. Rey et al. ${ }^{19}$ found that moisture changes the oxygen condition and microbial activity of soil environment, thus affecting SOC mineralization.

In recent years, the northeast of China has been increasingly affected by global climate change and human disturbance, which has exacerbated the process of soil salinization and desertification in Songnen Plain ${ }^{20}$. Land salinization has become one of the world's resource and environmental problems, which is a huge environmental pressure restricting the development of agriculture and causes billions of agricultural economic losses every year. Soil salinization is a kind of land degradation caused by excessive accumulation of soil salinization under the combined action of natural and human factors ${ }^{21}$. It can damage the normal growth of plants, change the structure and function of cell membrane, and have toxic effects on cells. Western Jilin Province, located in the Northeast China, is a typical vulnerable area for global carbon cycle research, and also one of the three major concentrated distribution areas of soda saline-alkali soil in the world ${ }^{22,23}$. Previous studies on soil carbon pool mainly focused on forest, wetland and grassland soils. However, the research on soil carbon pool in saline-alkali land is relatively weak, especially the SIC and the effects of soil enzymes and microorganisms is not clear ${ }^{24-26}$.

After decades of cultivation and development, a special saline alkali agroecosystem has been formed in the study area, with maize and rice as the main crops. We selected the rhizosphere soil of maize and rice as the research object. The aim of this study is to analyze the variation of physico-chemical properties, soil enzyme activities and microbial community structure of maize and rice rhizosphere soil and their effects of soil enzymes and microorganisms on the transformation of SOC and SIC in soda saline-alkali fields. It provides a basic example for the study of global carbon cycle in saline-alkali farmland, which is of great significance to the protection of saline-alkali land resources and the sustainable development of agriculture.

\section{Materials and methods}

Study area description. The study area is located in Songyuan City, which belongs to the west of Jilin Province (Fig. 1). The area has experienced multiple desertification and saline-alkali desertification evolution process, forming a large area of saline-alkali soil deposition ${ }^{27}$. The region is a semi-arid and semi humid continental monsoon climate zone, with obvious difference in four seasons. The average annual precipitation is $558.3 \mathrm{~mm}$, and the highest average temperature in July is $23.5^{\circ} \mathrm{C}$.

Soil sampling and experimental design. Maize and rice are the main crops in the study area, accounting for $90.12 \%$ of the total grain output in Songyuan City. They are easy to be planted on a large scale and have relatively high economic benefits. Therefore, we selected the rhizosphere soil of these two crops for study. In order to make the sample plots more representative and the test results more universal, we took samples according to the soil type map and land use type map, combined with field investigation. Maize and rice are both monocropped, sown in May and harvested in October. The fertilization and management measures of all the fields were consistent, and the fertilizers (urea, potassium and phosphorus) were applied once on May 8 .

Before sowing in April, we collected a large number of soil samples around Songyuan City and took them back to the laboratory for physico-chemical properties testing. We selected three maize fields and three rice fields with different levels of salinity during soil development, and the soil type was salinized meadow soil (Table 1). The second field sampling of rhizosphere soil was collected on August 16, 2019 (vigorous root growth stage), and 3 parallel sampling points were randomly selected at each site. We set up five sampling blocks $(15 \mathrm{~m} \times 15 \mathrm{~m})$ in each sampling field, and each sampling block contains three parallel sampling sites (Fig. 1). When sampling, all the roots of plants were dug out. Due to the difference between paddy fields and maize fields, we assume that the soil attached to root system is regarded as rhizosphere soil. Subsamples from the same block were mixed to generate a composite sample. A total of 30 composite samples of maize and rice were placed in sterile sealed bags, stored in incubators filled with ice, and quickly transported to the laboratory. The composite samples were divided into three parts: one part was ground after natural air drying in the laboratory, screened by $2 \mathrm{~mm}$ and $0.2 \mathrm{~mm}$ respectively, and bagged for standby; some parts were refrigerated at $4{ }^{\circ} \mathrm{C}$ for microbial enzyme activity test; the other part was stored at $-80^{\circ} \mathrm{C}$ for microbial community structure measurement. 


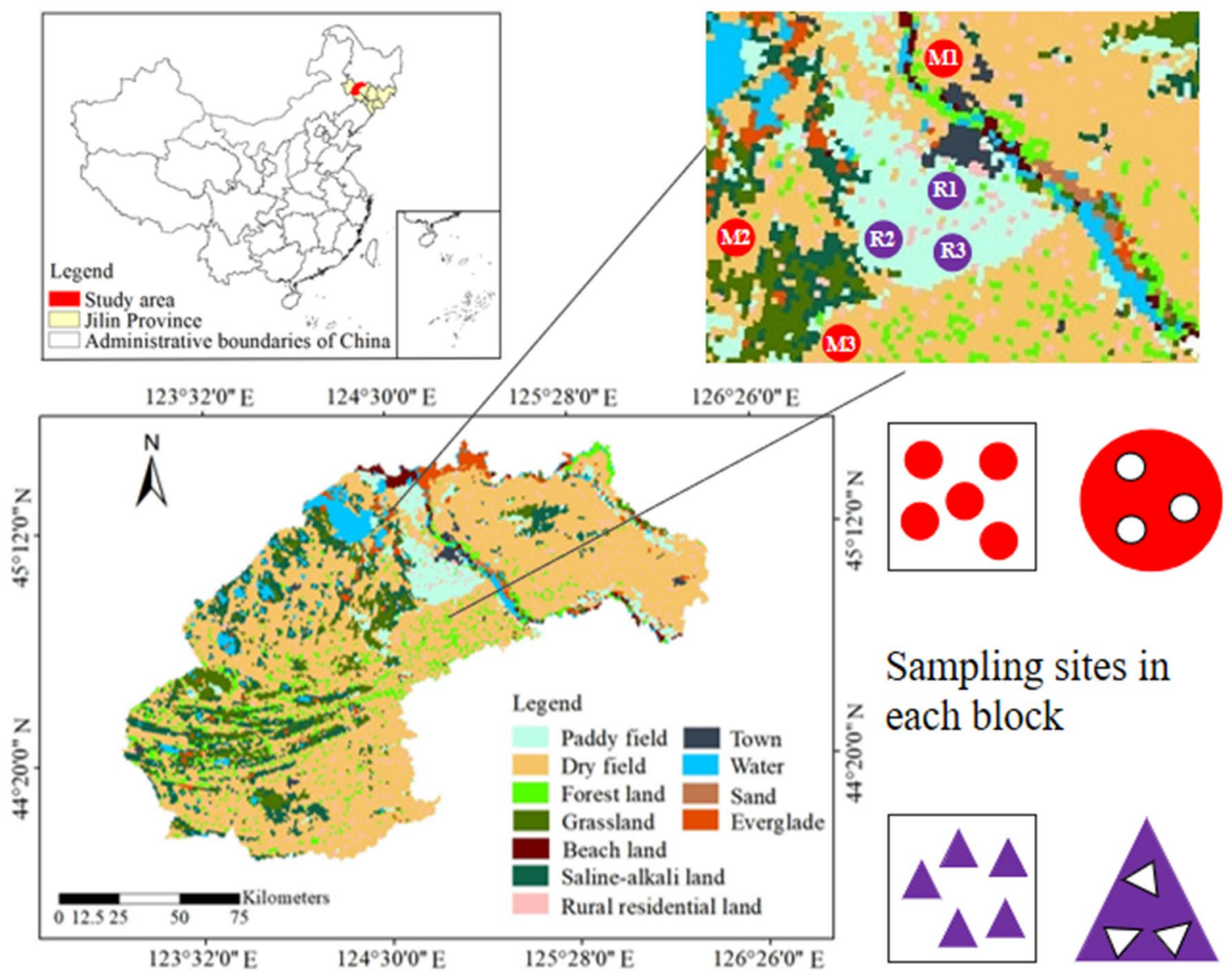

Figure 1. Location map of sampling sites in the study area (Songyuan).

\begin{tabular}{|l|l|l|l|l|l|l|l|l|}
\hline Samplingsites & Soil classifification & $\mathbf{p H}$ & Clay (\%) & Silt (\%) & Sand (\%) & $\begin{array}{l}\text { Fertilization } \\
\text { treatment }\end{array}$ & Experimentalarea & Type of crop \\
\hline M1 & Loam & 8.43 & 14.03 & 40.73 & 45.24 & N, P and K & $95 \mathrm{~m} \times 100 \mathrm{~m}$ & Maize \\
\hline M2 & Silty loam & 9.23 & 8.52 & 73.48 & 18.00 & N, P and K & $99 \mathrm{~m} \times 103 \mathrm{~m}$ & Maize \\
\hline M3 & Sandy loam & 9.98 & 7.94 & 24.98 & 47.08 & N, P and K & $90 \mathrm{~m} \times 100 \mathrm{~m}$ & Maize \\
\hline R1 & Loam & 8.23 & 14.07 & 40.18 & 45.75 & N, P and K & $98 \mathrm{~m} \times 102 \mathrm{~m}$ & Rice \\
\hline R2 & Silty loam & 9.37 & 10.75 & 67.33 & 21.92 & N, P and K & $97 \mathrm{~m} \times 101 \mathrm{~m}$ & Rice \\
\hline R3 & Sandy loam & 9.94 & 4.58 & 31.30 & 64.12 & N, P and K & $95 \mathrm{~m} \times 99 \mathrm{~m}$ & Rice \\
\hline
\end{tabular}

Table 1. Background information on sampling sites.

Physico-chemical analysis of soil. Soil pH, soil salt content(SSC), Alkali-N (AN), were determined on soil passed through the $2 \mathrm{~mm}$ sieve. SOM was determined on soil passed through the $0.2 \mathrm{~mm}$ sieve. Soil physicochemical properties were determined following the methods described by Zheng ${ }^{28}$. Soil texture was measured by Mastersizer 2000 laser particle size analyzer. Soil pH and SSC were determined by $\mathrm{pH}$ meter and residue drying-mass method in a ratio of 5-1 (water to soil), respectivily. SOM was determined by oil bath heating dichromate oxidation method. The concentration of exchangeable sodium (c mol $\left.\left(\mathrm{Na}^{+}\right) \mathrm{kg}^{-1}\right)$ was measured by using flame photometry (Shimadzu optical doublebeam atomic absorption spectrophotometer, Shanghai). Cation exchange capacity (CEC) $\left(\mathrm{c} \mathrm{mol} \mathrm{kg}{ }^{-1}\right)$ was determined by the EDTA-ammonium acetate salt exchange method. The exchangeable sodium percentage (ESP) was calculated by the following formula.

$$
\mathrm{ESP}=\mathrm{Na}{ }^{+} / \mathrm{CEC} \times 100
$$

Soil enzyme activities. Catalase activity (EC 1.11.1.6) was determined by potassium permanganate titration and was calculated after the blank subtraction according to the volume of consuming of $\mathrm{KMnO}_{4}$ standard solution. Soil invertase (EC 3.2.1.26) and amylase (EC 3.2.1.2) activities were determined by 3,5-Dinitrosalicylic acid colorimetry. Both of them were analyzed by spectrophotometry at $508 \mathrm{~nm}$, and the activity of invertase and amylase could be expressed as $\mathrm{mg} \mathrm{g}^{-1}$ according to the amount of reducing sugar generated after one day 


\begin{tabular}{|l|l|l|l|l|l|}
\hline Sampling sites & $\mathbf{p H}$ & ESP $(\%)$ & $\mathbf{S S C}(\%)$ & $\mathbf{S O M}\left(\mathrm{g} \mathrm{kg}^{-1}\right)$ & $\mathbf{A N}\left(\mathrm{g} \mathrm{kg}^{-1}\right)$ \\
\hline M1 & $8.52 \pm 0.29$ & $8.14 \pm 0.22$ & $0.24 \pm 0.04$ & $20.14 \pm 0.15$ & $0.11 \pm 0.04$ \\
\hline M2 & $9.08 \pm 0.23$ & $16.76 \pm 0.18$ & $0.37 \pm 0.03$ & $15.89 \pm 0.26$ & $0.10 \pm 0.02$ \\
\hline M3 & $9.45 \pm 0.21$ & $23.53 \pm 0.21$ & $0.52 \pm 0.05$ & $11.53 \pm 0.25$ & $0.08 \pm 0.02$ \\
\hline R1 & $8.57 \pm 0.19$ & $8.06 \pm 0.25$ & $0.23 \pm 0.05$ & $21.23 \pm 0.23$ & $0.12 \pm 0.05$ \\
\hline R2 & $9.11 \pm 0.17$ & $17.24 \pm 0.17$ & $0.38 \pm 0.04$ & $14.52 \pm 0.22$ & $0.11 \pm 0.03$ \\
\hline R3 & $9.47 \pm 0.23$ & $22.65 \pm 0.19$ & $0.45 \pm 0.03$ & $11.19 \pm 0.26$ & $0.09 \pm 0.03$ \\
\hline
\end{tabular}

Table 2. Physico-chemical properties of rhizosphere soil (ESP, exchangeable sodium percentage; SSC, soil salt content; SOM, soil organic matter; AN, Alkali-N).

of culture. The soil $\beta$-glucosidase activity (EC3.2.1.21) was measured by using p-nitrophenol- $\beta$-D-glucoside as substrate, $\mathrm{p}$-nitrophenol was hydrolyzed to produce $\mathrm{p}$-nitrophenol under the action of $\beta$-glucosidase, and the activity of $\beta$-glucosidase was colorimetrically determined at $400 \mathrm{~nm}$.

Soil microbial community analysis. Soil genomic DNA was extracted from the sample using the E.Z.N.A. soil DNA kit (Omega Biotek, GA 30,071, USA). The extracted DNA was purified and quantified by spectrophotometer. (Thermo, MA 02,451, USA). The forward and reverse primers were connected with the universal primer of Illumina Miseq high-throughput sequencing platform, and the PCR products with universal primer sequence at both ends were obtained by the first round PCR reaction using genomic DNA as template, and the PCR products obtained in the first round were purified. The PCR product of the sequence was obtained by connecting the two ends of the sequencing tag sequence with the primer sequence matched with the general primer sequence of the first round of PCR. The purified PCR product was used as the template for the second round of PCR reaction. The amplicon extracted from $2 \%$ agarose gel was purified by PCR purification kit (Beckman, Indiana 46,268, USA) and quantified using a Qubit ${ }^{\circledR} 2.0$ fluorimeter (Invitrogen, CA 92,008, USA). The Illumina MiSeq high-throughput sequencing platform was used for sequencing (Shanghai Sangon Biotechnology Co., LTD., Shanghai, China).

SOC and SIC aanalysis. Shimadzu TOC-V (Japan) was used to determine the SOC and SIC. The TOC (total organic carbon) instrument uses combustion oxidation-non-dispersive infrared absorption method for total organic carbon. Using high purity air $\left(\mathrm{N}_{2}+\mathrm{O}_{2}\right)$ as carrier gas, quantitative soil samples were added to the total carbon (TC) and IC (inorganic carbon) reaction chamber, respectively. The TC and IC were measured under their respective working conditions, and the TOC was calculated (TOC $=$ TC-IC). Test conditions: carrier gas (high purity oxygen) pressure: $300 \mathrm{kPa}$; flow rate: $500 \mathrm{ml} / \mathrm{min}$. TC condition: temperature $900{ }^{\circ} \mathrm{C}$, cobalt oxide platinum catalyst. IC condition: temperature $200{ }^{\circ} \mathrm{C}, 25 \%$ phosphoric acid (superior purity) is reactive acid. Glucose (superior purity) and anhydrous sodium carbonate (Reference Reagent) are used as standard samples of TC and IC respectively.

Statistical analysis. The remote sensing data of China's land use are based on Landsat 8 remote sensing images and generated through manual visual interpretation. The interpretation data are available for free download on the website of Institute of Geographic Sciences and Natural Resources Research, CAS, Chinese Academy of Sciences and the data center (https://www.resdc.cn/data.aspx?DATAID=335) and created by ArcGIS 10.2 platform (http://www.esri.com/sofware/arcgis/arcgis-for-desktop) for the study area. The experimental data were expressed as mean \pm standard deviation (SD). SPSS (SPSS Inc., Chicago, IL, USA; Norusis, 2008) was used for one-way analysis of variance (ANOVA), and the significant differences of SOC, SIC and enzyme activities were obtained. Duncan's test was used to evaluate significance when $P<0.05$. The graph was drawn by using the software package origin 8.5. Redundancy analysis (RDA) was carried out by Canoco5 software (Microcomputer Power, Inc., Ithaca, NY, USA).

\section{Results}

Soil physico-chemical properties. The soil physico-chemical properties of the six farmlands were summarized in Table 2. Mean values of rhizosphere soil pH in maize fields were lowest at M1 (8.52), medium at M2 (9.08), and highest at M3 (9.45). In rice fields, the mean $\mathrm{pH}$ values were lowest at R1 (8.57), medium at R2 (9.11) and highest at R3 (9.47). These trends (in both maize and rice fields) were positively related with ESP in each field, M1 had the lowest ESP value of $8.14 \%$, and M3 had the highest value of $23.53 \%$. The SSC content in maize and rice fields ranged from 0.24 to $0.52 \%$ and 0.23 to $0.45 \%$ respectively. The maximum occurs in M 3 and R3. The content of SOM and AN decreased with the increase of soil $\mathrm{pH}$ and ESP.

Soil carbon distribution. SOC in maize fields and paddy fields decreased with the increase of soil salinity (Fig. 2a). SOC in maize field was $11.68-22.37 \mathrm{~g} \mathrm{~kg}^{-1}$, and that in paddy field was $11.19-21.23 \mathrm{~g} \mathrm{~kg}^{-1}$. SIC in maize field and rice field increased with the increase of soil salinity. SIC in maize and rice were $6.03-8.83 \mathrm{~g} \mathrm{~kg}^{-1}$ and $3.44-6.43 \mathrm{~g} \mathrm{~kg}^{-1}$, respectively (Fig. 2b). SOC was significantly different in maize fields and rice fields, the same as $\operatorname{SIC~}(P<0.05)$. 

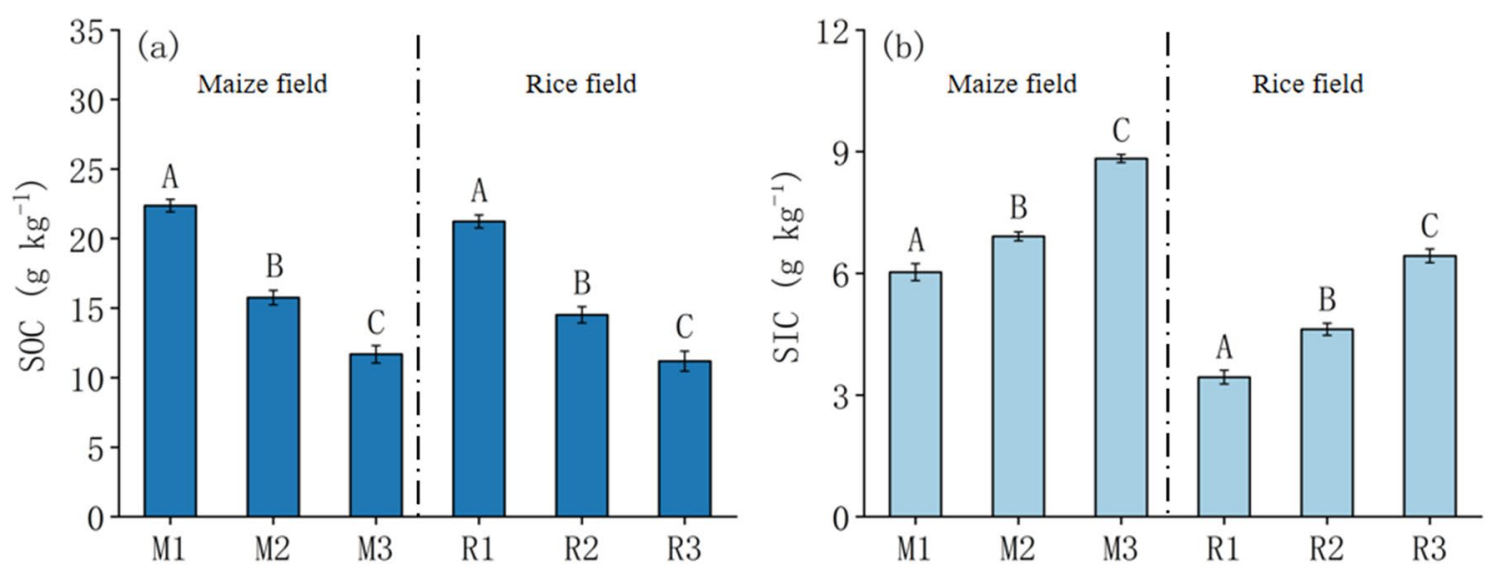

Figure 2. SOC and SIC distribution in the rhizosphere soil of maize (M) and rice (R) in different saline-alkali fields. Capital letters indicate the significance of the same crop in different fields $(P<0.05)$.

\begin{tabular}{|l|l|l|l|l|}
\hline Sampling sites & Catalase $\left(\mathbf{m g ~ g}^{-1}\right)$ & Invertase $\left(\mathbf{m g ~ g}^{-1}\right)$ & Amylase $\left(\mathbf{m g ~ g}^{-1}\right)$ & $\beta$-glucosidase $\left(\mathbf{m g ~ g}^{-1}\right)$ \\
\hline M1 & $5.60 \pm 0.14 \mathrm{Aa}$ & $6.14 \pm 0.08 \mathrm{Ab}$ & $1.39 \pm 0.02 \mathrm{Ac}$ & $0.57 \pm 0.03 \mathrm{Ad}$ \\
\hline M2 & $4.97 \pm 0.21 \mathrm{Ba}$ & $5.54 \pm 0.06 \mathrm{Bb}$ & $0.99 \pm 0.02 \mathrm{Bc}$ & $0.54 \pm 0.01 \mathrm{Ad}$ \\
\hline M3 & $4.38 \pm 0.11 \mathrm{Ca}$ & $4.54 \pm 0.06 \mathrm{Cb}$ & $0.96 \pm 0.03 \mathrm{Bc}$ & $0.52 \pm 0.04 \mathrm{Ad}$ \\
\hline$P 1$ & $7.58 \pm 0.09 \mathrm{Aa}$ & $5.62 \pm 0.05 \mathrm{Ab}$ & $1.89 \pm 0.05 \mathrm{Ac}$ & $0.49 \pm 0.03 \mathrm{Ad}$ \\
\hline$P 2$ & $6.54 \pm 0.11 \mathrm{Ba}$ & $5.30 \pm 0.08 \mathrm{Bb}$ & $1.81 \pm 0.04 \mathrm{Ac}$ & $0.49 \pm 0.03 \mathrm{Ad}$ \\
\hline$P 3$ & $6.29 \pm 0.16 \mathrm{Ba}$ & $3.41 \pm 0.03 \mathrm{Cb}$ & $1.45 \pm 0.04 \mathrm{Cc}$ & $0.44 \pm 0.01 \mathrm{Ad}$ \\
\hline
\end{tabular}

Table 3. Soil enzyme activities in the rhizosphere soil of maize $(M)$ and rice $(R)$ in different saline-alkali fields. Capital letters indicate the significance of the same crop in different fields $(P<0.05)$ and lowercase letters indicate the difference in soil enzyme activities of the same crop in the same field $(P<0.05)$.

\begin{tabular}{|l|l|l|l|l|l|}
\hline Sampling Sites & Shannon index & ACE index & Chaol index & Coverage & Simpson index \\
\hline M1 & 7.54 & 34,852 & 23,036 & 0.94 & 0.01 \\
\hline M2 & 7.31 & 17,410 & 12,868 & 0.95 & 0.03 \\
\hline M3 & 7.02 & 15,948 & 10,885 & 0.93 & 0.05 \\
\hline P1 & 8.00 & 32,016 & 21,388 & 0.94 & 0.01 \\
\hline P2 & 7.70 & 29,489 & 20,566 & 0.93 & 0.02 \\
\hline P3 & 7.08 & 19,368 & 11,617 & 0.95 & 0.05 \\
\hline
\end{tabular}

Table 4. Characteristics of soil bacterial richness and diversity indexes in the rhizosphere soil of maize (M) and rice $(\mathrm{R})$ in different saline-alkali fields.

Soil enzyme activities. The soil enzyme activities of maize and rice decreased with the increase of salinity (Table 3). The activities of catalase, invertase, amylase and $\beta$-glucosidase in maize fields were $4.38-5.60 \mathrm{mg} \mathrm{g}^{-1}$, $4.54-6.14 \mathrm{mg} \mathrm{g}^{-1}, 0.96-1.39 \mathrm{mg} \mathrm{g}^{-1}, 0.52-0.57 \mathrm{mg} \mathrm{g}^{-1}$, respectively. The results of soil enzyme in paddy field were $6.29-7.58 \mathrm{mg} \mathrm{g}^{-1}, 3.41-5.62 \mathrm{mg} \mathrm{g}^{-1}, 1.45-1.89 \mathrm{mg} \mathrm{g}^{-1}, 0.44-0.49 \mathrm{mg} \mathrm{g}^{-1}$, respectively. The amylase and catalase activities in rice fields were higher than those in maize fields. ANOVA revealed that there were significant differences in soil enzyme activities between maize fields with different salinity levels, and there were significant differences between different enzyme activities in the same sampling site. The analysis results of rice and maize samples were consistent.

Diversity index of soil microbial community. The Shannon index and Simpson index of soil microorganisms can accurately reflect the characteristic function of microbial community diversity of this component. There were differences in the diversity index of soil microbial community structure between saline-alkali maize and rice fields. Coverage index actually reflects whether sequencing results represent the real situation of the samples. The coverage of all samples was above $93 \%$, which indicated that the results of sequencing were relatively reliable and basically reflected the situation of soil bacteria. The Shannon, ACE and Chaol indexes of the six sampling sites revealed a similar trend, which were $\mathrm{M} 1>\mathrm{M} 2>\mathrm{M} 3, P 1>P 2>P 3$ (Table 4). 

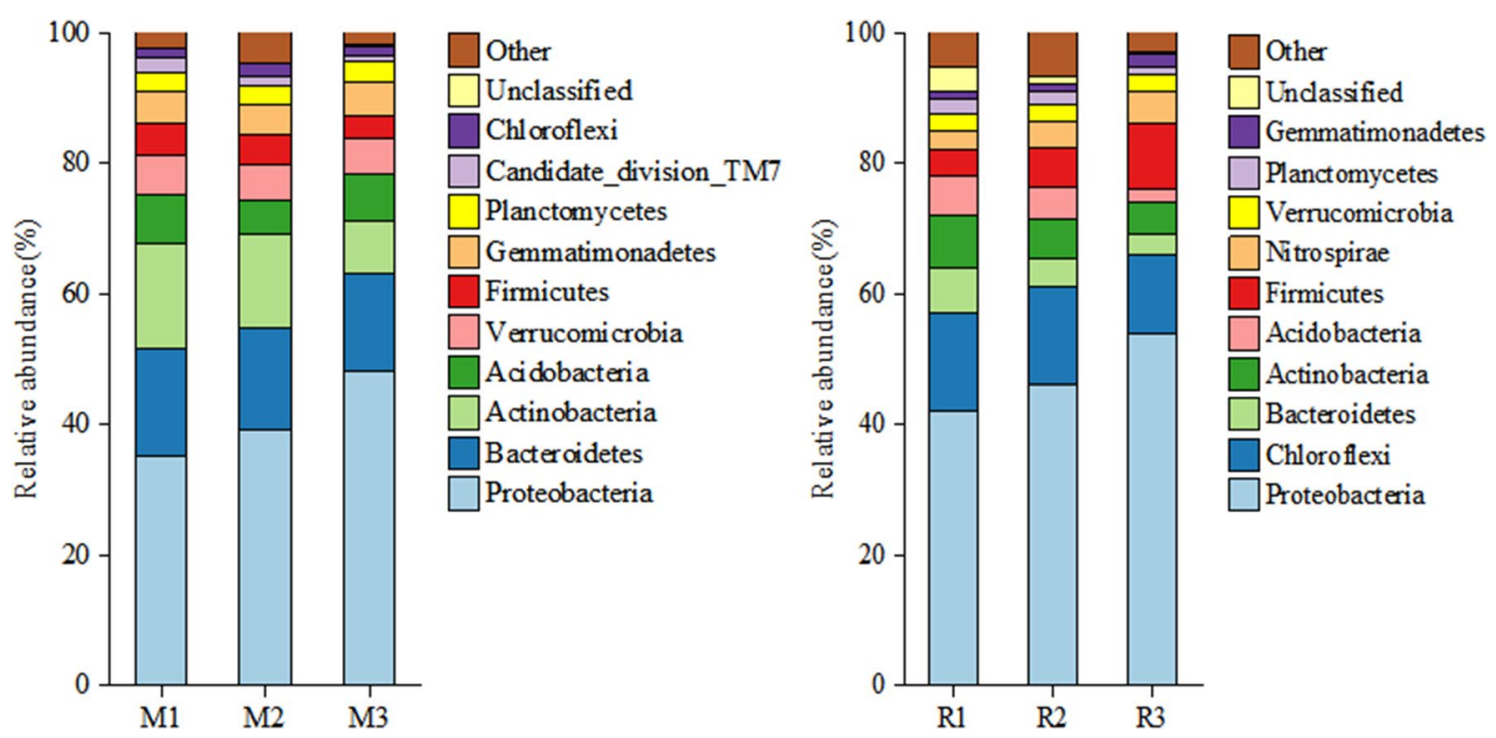

Figure 3. At the phylum level, soil bacterial community composition in the rhizosphere soil of maize (M) and rice $(\mathrm{R})$ in different saline-alkali fields.

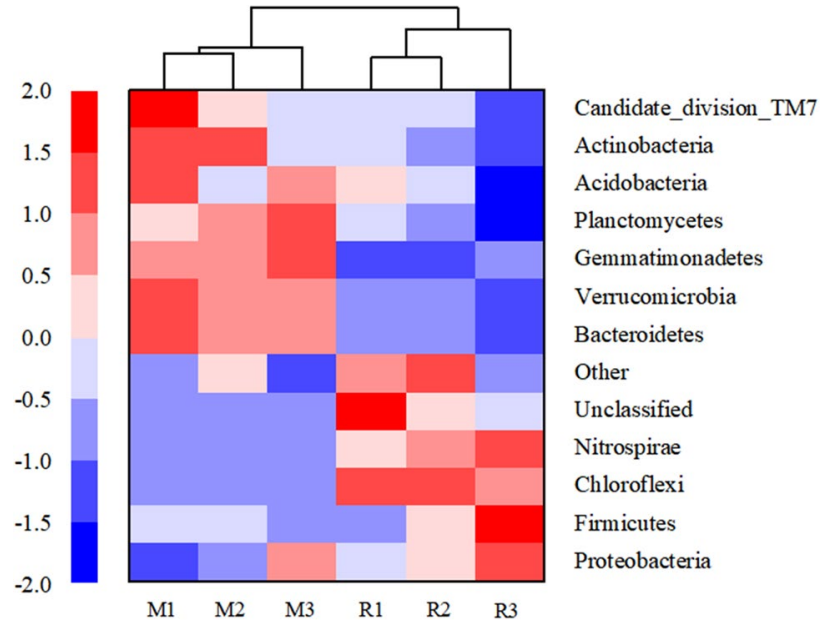

Figure 4. Heat map of microbial community structure in the rhizosphere soil of maize (M) and rice (R) in different saline-alkali fields.

Bacterial community structure. The bacterial $16 \mathrm{~S}$ rRNA genes collected from sampling sites were sequenced by high-throughput sequencing and cluster analysis. According to the relative abundance of bacteria at the phylum level (Fig. 3), saline-alkali stress significantly affected the rhizosphere soil bacterial community composition. At the phylum level, the main groups of soil bacterial communities in saline-alkali maize fields were Proteobacteria, Bacteroidetes, Actinobacteria, Verrucomicrobia, and the relative average abundance ratios were $40.08 \%, 15.68 \%, 12.80 \%, 6.69 \%$, and $5.50 \%$, respectively (Fig. 3). In the rhizosphere soil of maize (M), the sum of the relative abundance of the five bacterial phyla accounted for $81.54 \%$ of the total number of soil bacteria. Proteobacteria and Chloroflexi were the main groups of bacterial communities in saline-alkali rice fields at the phylum level, accounting for $61.33 \%$ of the total bacterial sequences recovered $(47.33$ and $14.00 \%$, respectively) (Fig. 3). The other major phyla (average relative abundance $>1 \%$ ) were Firmicutes (6.67\%), Actinobacteria (6.33\%), Bacteroidetes (4.80\%), Acidobacteria (4.33\%), Nitrospirae (4.00\%), Verrucomicrobia (2.63\%) and Planctomycetes $(1.87 \%)$. The sum of relative abundance of five phyla accounted for $91.96 \%$ of the total number of soil bacteria in the rhizosphere soil of rice (R). The relative average abundance ratio of Bacteroidetes and Actinobacteria in maize rhizosphere soil was $10.8 \%$ and $6.4 \%$ higher than that in rice rhizosphere soil, respectively, while the relative average abundance ratio of Chloroflexi in rice rhizosphere soil was $12.3 \%$ higher than that in maize rhizosphere soil.

The heat map of microbial communities at the phylum level showed that the abundance of bacteria in rhizosphere soil samples of maize and rice was different in different saline-alkali fields. The results of cluster analysis showed that the discrepancy between the relative and absolute abundances of bacteria in maize and rice rhizosphere samples in different saline-alkali fields (Fig. 4). Based on the results of cluster analysis the samples of 
(a)

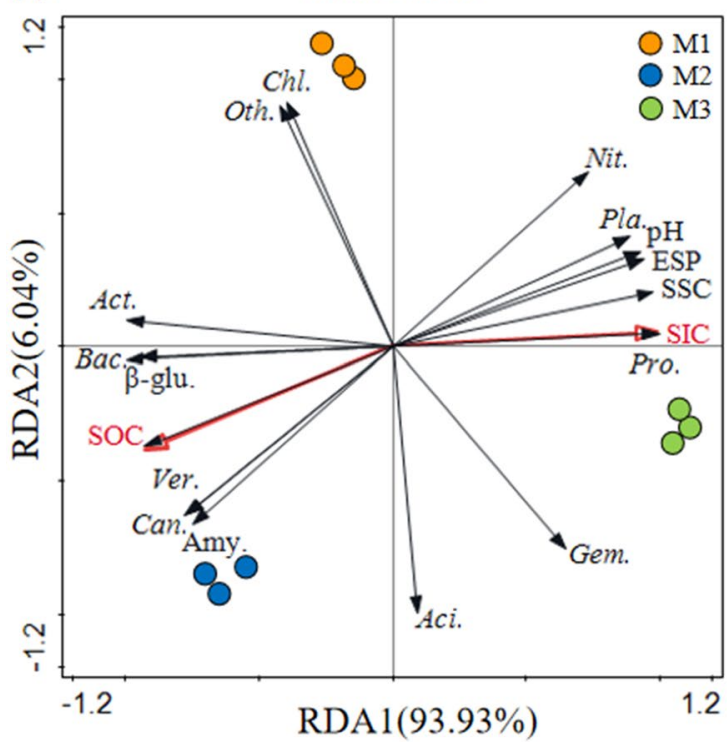

(b)

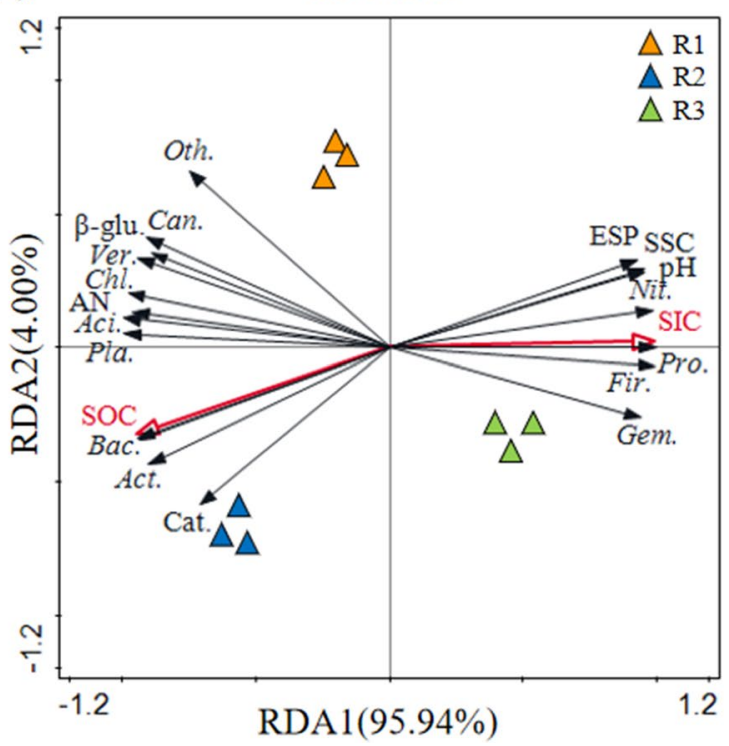

Figure 5. Redundancy discrimination analysis (RDA) depicting the relationship between the main soil physico-chemical parameters, soil enzymes and microorganism in the rhizosphere soil of maize $(\mathrm{M})$ and rice (R) in different saline-alkali fields (Nit., Nitrospirae; Pla., Planctomycetes; Pro., Proteobacteria; Gem., Gemmatimonadetes; Aci., Acidobacteria; Chl., Chloroflexi; Oth., Other; Act., Actinobacteria; Unc.,Unclassified; Fir., Firmicutes; $\beta$-glu., $\beta$-glucosidase; Can., Candidate-division-TM7; Ver., Verrucomicrobia; Bac., Bacteroidetes; Amy., Amylase; Cat., Catalase).

M1 and M2, R1 and R2 were clustered into two close groups, respectively, while the samples of M3 and R3 were relatively far away from those groups (Fig. 4).

\section{Discussion}

Effects of physico-chemical properties on the variations of SOC and SIC. Soil physico-chemical properties are affected not only by SOC, but also by soil mineral composition, especially SIC. Soil pH is the most sensitive indicator to regulate the cycle and sequestration of SOC, and to affect crop growth, soil microbial and enzyme activities $\mathrm{s}^{29-31}$. The optimal $\mathrm{pH}$ of bacteria was $6.5-8$, and that of fungi was 5-6 $6^{32}$. The soil $\mathrm{pH}$ of M3 and $\mathrm{R} 3$, is 9.36 and 9.32 , respectively, which inhibits soil microbial activity, thus affecting the humification process of roots and litter, and hindering the input and accumulation of $\mathrm{SOC}^{33}$. The reason for the high $\mathrm{pH}$ is that the sodium ions adsorbed on the soil colloid hydrolyze and produce $\mathrm{OH}^{-}$ions, which increase the alkalinity of the soil. In the case of saturated soil colloids, the exchange of sodium hydrolysis may cause soil alkalinity reaction. There was a significant correlation between ESP and $\mathrm{pH}$, and a negative correlation between ESP and SOC (Fig. 5) indicating that higher ESP was not conducive to SOC sequestration. In the process of soil root development, SOM will be secreted to increase SOC content. Because there are more carbonate and bicarbonate in the soil, the higher soil $\mathrm{pH}$ also promotes the accumulation of SIC. SOC had a negative correlation with SIC, that is, the content of SIC in rhizosphere soil decreased with the increase of SOC content, which was consistent with the research results of Huang et al. ${ }^{34}$.

Effects of enzyme activities on the variations of SOC and SIC. Determination of enzyme activities, including catalase, invertase, amylase and $\beta$-glucosidase, in the rhizosphere soil of maize and rice in different saline-alkali fields is helpful to understand soil biochemical reactions ${ }^{35}$. The results showed that the activities of catalase, invertase, amylase and $\beta$-glucosidase decreased with the increase of salinity (Table 3). Saline-alkali stress changes the structure and function of cell membrane and has toxic effects on cells. At the same time, it increases the soil osmotic pressure, hinders the absorptive capacity of plants, limits the growth of plants, makes the root system cannot fully develop, directly affects the secretion of enzymes, leading to great differences in enzyme activities in different soil regions ${ }^{36}$. The increase of SSC will reduce the activities of soil enzymes. Compared with $\mathrm{CaCl}_{2}$ and $\mathrm{Na}_{2} \mathrm{SO}_{4}, \mathrm{NaCl}$ has a stronger inhibitory effect on soil enzymes and microbial activities ${ }^{37}$. However, under high saline-alkali stress conditions, enzyme can still promote the conversion of soil carbon. The results showed that the activity of amylase and catalase in rice field was higher than that in maize field, which may be due to the fact that rice was in the irrigation stage, and the hydrothermal conditions promoted the growth and reproduction of microorganisms. Under suitable growth conditions, plant roots will secrete more organic acids and carbohydrates, stimulating the activities of catalase and amylase. In the process of catalyzing the decomposition of hydrogen peroxide, soil catalase will release oxygen, which is conducive to the life activities of aerobic microorganisms in the soil, thus increasing the soil humification intensity and SOC content. Amylase catalyzes SOM to increase SOC content in soil ${ }^{38}$. Compared with maize, rice rhizosphere soil is in the state of 
water for a long time, which is easy to lead to a large amount of hydrogen peroxide accumulation, so the soil catalase is more active.

Effects of microorganisms on the variations of SOC and SIC. In the mature stage of maize and rice, the water and heat conditions are suitable, the rhizosphere exudates provide nutrients for microorganisms, and the plant growth and soil quality tend to be stable. Bacteria changed the most under different saline-alkali degree and were always the dominant microorganisms in saline-alkali soil. It was found that at the phylum level, a variety of bacteria decreased with the increase of salinity. It may be that Firmicutes, Proteobacteria and Nitrospirae will increase sharply in adversity ${ }^{39,40}$. And they were significantly affected by $\mathrm{pH}$ and ESP, and were positively correlated with SIC in saline-alkali rice rhizosphere soils $(P<0.05)$ (Fig. 5). The main reasons for community diversity difference were that the higher salinity inhibited the number and activity of microorganisms and the inhomogeneity of microbial species. With the increase of salinization degree, the activity and population number of microorganisms decreased under the adverse growth conditions of saline-alkali soil, which reduced the amount of plant derived SOC fixed into soil by microorganisms $s^{41-43}$. In the long run, the carbon release rate of slow circulation pool has an important impact on ecosystem carbon storage during salinization ${ }^{44}$. Microorganisms play a key role in the formation of carbonate. Microorganisms can accelerate karstification and promote $\mathrm{CO}_{2}$ deposition. It can also produce acid through metabolic activities, resulting in dissolution of carbonate and release of $\mathrm{CO}_{2}$. Microorganisms can also form carbonate from $\mathrm{CO}_{2}$ produced by respiration. Microbial community plays a key role in the decomposition and transformation of soil carbon. Proteobacteria, Actinobacteria, Bacteroidetes and Acidobacteria are relatively high in maize and rice rhizosphere soils, which may contribute to nutrient uptake by root system and maintain the balance of microenvironment, so as to improve the soil environment and enhance the ability to resist saline-alkali stress. Therefore, they are valuable resources for biological improvement of saline-alkali soil regions.

\section{Conclusions}

(1) Saline-alkali stress changed rhizosphere soil physico-chemical properties and affected soil enzyme activities. The activities of catalase, invertase, amylase and $\beta$-glucosidase decreased with the increase of salinity, i.e., M1 $>$ M2 $>$ M3, R1 $>$ R2 $>$ R3, with significant differences $(P>0.05)$, and the activities of amylase and catalase in rice rhizosphere soil was higher than that in maize rhizosphere soil.

(2) Saline-alkali stress changes the community structure of rhizosphere soil. At the phylum level, most of bacteria decreased with the increase of salinity. On the contrary, compared with $\mathrm{M} 1$, the relative abundance of Proteobacteria and Firmicutes in M2 and M3 increased by $16.86 \%$ and $48.43 \%, 34.50 \%$ and $46.19 \%$, respectively. Compared with R1, the relative abundance of Firmicutes, Proteobacteria and Nitrospirae in R2 and R3 increased by $47.50 \%$ and $142.50 \%, 9.52 \%$ and $28.57 \%$ and $36.67 \%$ and $76.67 \%$, respectively.

(3) There was a significant correlation between ESP and $\mathrm{pH}$, and a negative correlation with SOC $(P<0.05)$ of maize and rice rhizosphere soil in soda saline-alkali field. Proteobacteria, Gemmatimonadetes, Planctomycetes and Nitrospirae were significantly affected by $\mathrm{pH}$ and ESP, and were positively correlated with SIC in saline-alkali maize and rice rhizosphere soils $(P<0.05)$.

\section{Data availability}

All data generated or analysed during this study are included in this published article.

Received: 21 June 2021; Accepted: 10 January 2022

Published online: 25 January 2022

\section{References}

1. Canadell, J. G. et al. Factoring out natural and indirect human effects on terrestrial carbon sources and sinks. Environ. Sci. Policy 10, 370-384. https://doi.org/10.1016/j.envsci.2007.01.009 (2007).

2. Bradford, M. A., Fierer, N. \& Reynolds, J. F. Soil carbon stocks in experimental mesocosms are dependent on the rate of labile carbon, nitrogen and phosphorus inputs to soils. Funct. Ecol. 22, 964-974. https://doi.org/10.1111/j.1365-2435.2008.01404.x (2008).

3. He, S., Liang, Z., Han, R., Wang, Y. \& Liu, G. Soil carbon dynamics during grass restoration on abandoned sloping cropland in the hilly area of the Loess Plateau China. Catena 137, 679-685. https://doi.org/10.1016/j.catena.2015.01.027 (2016).

4. Schuman, G. E., Janzen, H. H. \& Herrick, J. E. Soil carbon dynamics and potential carbon sequestration by rangelands. Environ. Pollut. 116, 391-396. https://doi.org/10.1016/s0269-7491(01)00215-9 (2002).

5. Duan, C. et al. Reveal the response of enzyme activities to heavy metals through in situ zymography. Ecotoxicol. Environ. Saf. 156, 106-115. https://doi.org/10.1016/j.ecoenv.2018.03.015 (2018).

6. Yang, J. et al. A proposal of "core enzyme" bioindicator in long-term $\mathrm{Pb}-\mathrm{Zn}$ ore pollution areas based on topsoil property analysis. Environ. Pollut. 213, 760-769. https://doi.org/10.1016/j.envpol.2016.03.030 (2016).

7. Fierer, N. Embracing the unknown: Disentangling the complexities of the soil microbiome. Nat. Rev. Microbiol. 15, 579-590. https://doi.org/10.1038/nrmicro.2017.87 (2017).

8. Wan, Z. \& Song, C. Advance on response of soil enzyme activity to ecological environment. Chin. J. Soil Sci. 40(4), 951-956 (2009).

9. Liu, G. et al. Soil enzymes as indicators of saline soil fertility under various soil amendments. Agric. Ecosyst. Environ. 237, 274-279 (2017).

10. Li, Z., Chaonian, F., Mengjie, L. \& Huanchao, Z. Nutrient and biological characteristics of different salinized soils in coastal areas of northern Jiangsu Province. J. Anhui Agric. Univ. 46, 86-92 (2019).

11. Bueis, T., Turrion, M. B., Bravo, F., Pando, V. \& Muscolo, A. Factors determining enzyme activities in soils under Pinus halepensis and Pinus sylvestris plantations in Spain: A basis for establishing sustainable forest management strategies. Ann. For. Sci. https:// doi.org/10.1007/s13595-018-0720-z (2018). 
12. Sinsabaugh, R. L. et al. Stoichiometry of soil enzyme activity at global scale. Ecol. Lett. 11, 1252-1264. https://doi.org/10.1111/j. 1461-0248.2008.01245.x (2008).

13. Marx, M. C., Kandeler, E., Wood, M., Wermbter, N. \& Jarvis, S. C. Exploring the enzymatic landscape: Distribution and kinetics of hydrolytic enzymes in soil particle-size fractions. Soil Biol. Biochem. 37, 35-48. https://doi.org/10.1016/j.soilbio.2004.05.024 (2005).

14. Bais, et al. The role of root exudates in rhizosphere interations with plants and other organisms. Annu. Rev. Plant Biol. 2006(57), 233-266 (2006).

15. Qu, Y. et al. Soil enzyme activity and microbial metabolic function diversity in soda saline-alkali rice paddy fields of northeast China. Sustainability 12, 15. https://doi.org/10.3390/su122310095 (2020).

16. Salinas-Garcia, J. R. et al. Tillage effects on microbial biomass and nutrient distribution in soils under rain-fed corn production in central-western Mexico. Soil Till. Res. 66, 143-152. https://doi.org/10.1016/s0167-1987(02)00022-3 (2002).

17. Roldán, A., Salinas-García, J. R., Alguacil, M. M. \& Caravaca, F. Changes in soil enzyme activity, fertility, aggregation and C sequestration mediated by conservation tillage practices and water regime in a maize field. Appl. Soil Ecol. 30, 11-20. https://doi. org/10.1016/j.apsoil.2005.01.004 (2005).

18. Lenton, T. M. \& Huntingford, C. Global terrestrial carbon storage and uncertainties in its temperature sensitivity examined with a simple model. Glob. Change Biol. 9, 1333-1352. https://doi.org/10.1046/j.1365-2486.2003.00674.x (2003).

19. Rey, A., Petsikos, C., Jarvis, P. G. \& Grace, J. Effect of temperature and moisture on rates of carbon mineralization in a Mediterranean oak forest soil under controlled and field conditions. Eur. J. Soil Sci. 56(5), 589-599 (2005).

20. Wang, X., Zhag, Y., Lv, J. \& Fan, X. Effect of long term different fertilization on properties of soil organic matter and humic acids. Sci. Agric. Sinica 33, 78-84 (2000).

21. Wei, Y. et al. Updated information on soil salinity in a typical oasis agroecosystem and desert-oasis ecotone: Case study conducted along the Tarim River. China. Sci. Total Environ. https://doi.org/10.1016/j.scitotenv.2019.135387 (2019).

22. Huang, L. H. et al. Impact of cultivation year, nitrogen fertilization rate and irrigation water quality on soil salinity and soil nitrogen in saline-sodic paddy fields in Northeast China. J. Agric. Sci. 154, 632-646. https://doi.org/10.1017/s002185961500057x (2015).

23. Liu, Q., Cui, B. \& Yang, Z. Dynamics of the soil water and solute in the sodic saline soil in the Songnen Plain China. Environ. Earth Sci. 59, 837-845. https://doi.org/10.1007/s12665-009-0079-4 (2009).

24. $\mathrm{Lu}, \mathrm{Y} . \& \mathrm{Xu}, \mathrm{H}$. Distribution characteristic of soil organic carbon fraction in different types of wetland in Hongze Lake of China. Sci. World J. 2014, 487961. https://doi.org/10.1155/2014/487961 (2014).

25. Nitsch, P., Kaupenjohann, M. \& Wulf, M. Forest continuity, soil depth and tree species are important parameters for SOC stocks in an old forest (Templiner Buchheide, northeast Germany). Geoderma 310, 65-76. https://doi.org/10.1016/j.geoderma.2017.08. 041 (2018).

26. Zhang, Z., Lu, X., Song, X., Guo, Y. \& Xue, Z. Soil C, N and P stoichiometry of deyeuxia angustifolia and carex lasiocarpa wetlands in Sanjiang Plain, northeast China. J. Soil Sediment. 12, 1309-1315. https://doi.org/10.1007/s11368-012-0551-8 (2012).

27. Bian, J., Tang, J., Zhang, L., Ma, H. \& Zhao, J. Arsenic distribution and geological factors in the western Jilin province China. J. Geochem. Explor. 112, 347-356. https://doi.org/10.1016/j.gexplo.2011.10.003 (2012).

28. Zheng, B. Technical Guide for Soil Analysis (China Agriculture Press, 2013).

29. Paul, E. A. The nature and dynamics of soil organic matter: Plant inputs, microbial transformations, and organic matter stabilization. Soil Biol. Biochem. 98, 109-126. https://doi.org/10.1016/j.soilbio.2016.04.001 (2016).

30. Solly, E. F., Schoning, I., Herold, N., Trumbore, S. E. \& Schrumpf, M. No depth-dependence of fine root litter decomposition in temperate beech forest soils. Plant Soil 393, 273-282. https://doi.org/10.1007/s11104-015-2492-7 (2015).

31. Steinweg, J. M., Kostka, J. E., Hanson, P. J. \& Schadt, C. W. Temperature sensitivity of extracellular enzymes differs with peat depth but not with season in an ombrotrophic bog. Soil Biol. Biochem. 125, 244-250. https://doi.org/10.1016/j.soilbio.2018.07.001 (2018).

32. Hartman, W. H., Richardson, C. J., Vilgalys, R. \& Bruland, G. L. Environmental and anthropogenic controls over bacterial communities in wetland soils. P. Natl. Acad. Sci. USA 105, 17842-17847. https://doi.org/10.1073/pnas.0808254105 (2008).

33. Andersen, R., Chapman, S. J. \& Artz, R. R. E. Microbial communities in natural and disturbed peatlands: A review. Soil Biol. Biochem. 57, 979-994. https://doi.org/10.1016/j.soilbio.2012.10.003 (2013).

34. Huang, B., Wang, J., Jin, H. \& Xu, S. Effects of long- term application fertilizer on carbon storage in calcareous meadow soil. J. Agro-Environ. Sci. 25, 161-164 (2006).

35. Bacmaga, M., Wyszkowska, J. \& Kucharski, J. Bioaugmentation of soil contaminated with azoxystrobin. Water Air Soil Poll. 228, 9. https://doi.org/10.1007/s11270-016-3200-9 (2017).

36. Miller, G., Suzuki, N., Ciftci-Yilmaz, S. \& Mittler, R. Reactive oxygen species homeostasis and signalling during drought and salinity stresses. Plant Cell Environ. 33, 453-467 (2010).

37. Pathak, H. \& Rao, D. L. N. Carbon and nitrogen mineralization from added organic matter in saline and alkali soils. Soil Biol. Biochem. 30, 695-702. https://doi.org/10.1016/S0038-0717(97)00208-3 (1998).

38. Xiao, Y. et al. Response of soil labile organic carbon fractions to forest conversions in subtropical China. Trop. Ecol. 57, 691-699 (2016).

39. Broszat, M. et al. Wastewater irrigation increases the abundance of potentially harmful gammaproteobacteria in soils in Mezquital Valley. Mexico. Appl. Environ. Microbiol. 80, 5282-5291 (2014).

40. Liu, Y. et al. Alphaproteobacteria dominate active 2-methyl-4-chlorophenoxyacetic acid herbicide degraders in agricultural soil and drilosphere. Environ. Microbiol. 13, 991-1009 (2011).

41. Baumann, K. et al. Soil microbial diversity affects soil organic matter decomposition in a silty grassland soil. Biogeochemistry 114, 201-212 (2013).

42. Philippot, L. et al. Loss in microbial diversity affects nitrogen cycling in soil. ISME J. 7, 1609-1619 (2013).

43. Chambers, L. G., Guevara, R., Boyer, J. N., Troxler, T. G. \& Davis, S. E. Effects of salinity and inundation on microbial community structure and fFunction in a mangrove peat soil. Wetlands 36, 361-371 (2016).

44. Wong, V. N. L., Greene, R. S. B., Dalal, R. C. \& Murphy, B. W. Soil carbon dynamics in saline and sodic soils: A review. Soil Use Manage. 26, 2-11 (2010).

\section{Acknowledgements}

We gratefully acknowledge National Natural Science Foundation of China (Nos. 51179073, 41471152) and Specialized Research Fund for Doctoral Program of Higher Education of China (20130061110065).

\section{Author contributions}

Y.Q. and J.T. designed the research; B.L., H.L. and S.W. tested the samples; Y.D. and Y.Y. analyzed the data; Y.Q. drafted the manuscript which was revised by J.T. and Z.L. All authors reviewed the manuscript.

\section{Competing interests}

The authors declare no competing interests. 


\section{Additional information}

Correspondence and requests for materials should be addressed to Z.L.

Reprints and permissions information is available at www.nature.com/reprints.

Publisher's note Springer Nature remains neutral with regard to jurisdictional claims in published maps and institutional affiliations.

(c) (1) Open Access This article is licensed under a Creative Commons Attribution 4.0 International License, which permits use, sharing, adaptation, distribution and reproduction in any medium or format, as long as you give appropriate credit to the original author(s) and the source, provide a link to the Creative Commons licence, and indicate if changes were made. The images or other third party material in this article are included in the article's Creative Commons licence, unless indicated otherwise in a credit line to the material. If material is not included in the article's Creative Commons licence and your intended use is not permitted by statutory regulation or exceeds the permitted use, you will need to obtain permission directly from the copyright holder. To view a copy of this licence, visit http://creativecommons.org/licenses/by/4.0/.

(C) The Author(s) 2022 